\title{
Functional role of AKT signaling in bovine early embryonic development: potential link to embryotrophic actions of follistatin
}

Mohamed Ashry 1,3,4, Sandeep K. Rajput 1,3, Joseph K. Folger ${ }^{1,3}$, Jason G. Knott ${ }^{2,3}$, Nabil A. Hemeida4,

Omaima M. Kandil ${ }^{5}$, Refaat S. Ragab ${ }^{4}$ and George W. Smith ${ }^{1,3^{*}}$

\begin{abstract}
Background: TGF- $\beta$ signaling pathways regulate several crucial processes in female reproduction. AKT is a non-SMAD signaling pathway regulated by TGF- $\beta$ ligands essential for oocyte maturation and early embryonic development in the mouse, but its regulatory role in bovine early embryonic development is not well established. Previously, we demonstrated a stimulatory role for follistatin (a binding protein for specific members of TGF- $\beta$ superfamily) in early bovine embryonic development. The objectives of the present studies were to determine the functional role of AKT signaling in bovine early embryonic development and embryotrophic actions of follistatin.
\end{abstract}

Methods: We used AKT inhibitors III and IV as pharmacological inhibitors of AKT signaling pathway during the first $72 \mathrm{~h}$ of in vitro embryo culture. Effects of AKT inhibition on early embryonic development and AKT phosphorylation were investigated in the presence or absence of exogenous follistatin.

Results: Pharmacological inhibition of AKT signaling resulted in a significant reduction in early embryo cleavage, and development to the 8- to 16-cell and blastocyst stages (d7). Treatment with exogenous follistatin increased AKT phosphorylation and rescued the inhibitory effect of AKT inhibitors III and IV on AKT phosphorylation and early embryonic development.

Conclusions: Collectively, results suggest a potential requirement of AKT for bovine early embryonic development, and suggest a potential role for follistatin in regulation of AKT signaling in early bovine embryos.

Keywords: AKT, Follistatin, TGF- $\beta$, AKT inhibitor, Bovine, Embryos

\section{Background}

Poor oocyte quality limits the efficiency of in vitro embryo production in cattle and women [1]. Our previous studies demonstrated a positive association between the transcript abundance of follistatin and oocyte developmental competence using the prepubertal calf and brilliant cresyl blue screening models [2, 3]. We also found that maternally derived follistatin is essential for bovine early embryonic development and exogenous supplementation of follistatin during first $72 \mathrm{~h}$ (h) of in vitro embryo culture has a stimulatory effect on early

\footnotetext{
*Correspondence: smithge7@msu.edu

'Laboratory of Mammalian Reproductive Biology and Genomics, Michigan

State University, East Lansing, Ml 48824, USA

${ }^{3}$ Department of Animal Science, Michigan State University, East Lansing, MI 48824, USA

Full list of author information is available at the end of the article
}

cleavage, embryonic development to 8- to 16-cell and blastocyst stages and blastocyst cell lineage allocation [4]. The functional requirement of follistatin in oocyte and early embryonic development has been described in bovine and other mono-ovulatory species [5].

Follistatin is a transforming growth factor $\beta$ (TGF- $\beta$ ) superfamily binding protein that may exert its embryotrophic effects through modulation of one or more of the SMAD $[6,7]$ or non-SMAD [8-10] signaling pathways. We previously demonstrated that the embryotrophic actions of follistatin on development to 8- to 16-cell and blastocyst stages are linked to the SMAD signaling pathways $[11,12]$. However, how follistatin promotes early embryonic development, particularly early cleavage, is still not fully understood. 
Follistatin was first identified as a high affinity Activin binding protein [13] and its binding affinity to select bone morphogenetic proteins (BMPs) has also been established [14, 15]. Both BMPs [16] and Activin [17] are major regulators of AKT signaling pathway that promotes cell cycle progression during G2/M transition. Studies have shown that AKT stimulates the transition from metaphase I (MI) to metaphase II (MII) in bovine [18], porcine [19], mouse [20, 21] and Xenopus [22] oocytes by activation of Phosphodiesterase 3A (PDE3A) and cyclin dependent kinase 1 (CDK1) required for resumption and regulation of meiosis. AKT was primarily identified as a serine/threonine specific protein kinase that functions downstream of Phosphatidylinositol 3kinase (PI3K) [23]. Inhibition of AKT with a synthetic small molecule inhibitor (AKT inhibitor III) resulted in arrest of bovine oocytes at MI stage [18]. AKT plays an important role during entry of one cell mouse embryos into the first mitosis as inhibition of AKT resulted in arrest of cell cycle in G1 and G2 phases [24]. Moreover, inhibition of AKT activity compromised the development of mouse embryos to the blastocyst stage [25, 26]. Considering the role of AKT in cell cycle progression in oocytes and embryos, we hypothesized that AKT signaling is required for bovine early embryonic development and is linked to the embryotrophic actions of follistatin during in vitro embryo culture. To test this hypothesis, we determined the functional role of AKT in bovine early embryonic development and investigated the relationship between AKT signaling and the embryotrophic actions of follistatin. Effects of treatment with the AKT inhibitors III and IV on development of early bovine embryos and AKT phosphorylation were analyzed. Effects of exogenous follistatin supplementation on AKT phosphorylation and developmental potential of AKT inhibitor treated embryos were also investigated.

\section{Methods}

All chemicals and reagents used were purchased from Sigma- Aldrich (St. Louis, MO) unless stated otherwise.

\section{Oocyte collection and in vitro embryo production}

Bovine oocytes were retrieved from ovaries collected at local abattoir in the state of Michigan. Oocyte aspiration, in vitro maturation (IVM), in vitro fertilization (IVF), and in vitro embryo culture (IVC) were performed as previously described [3, 27]. Briefly, morphologically good quality cumulus oocyte complexes (COCs), which have three or more layers of compact cumulus cell and granular, homogenous cytoplasm, were matured in TCM-199 media [supplemented with $50 \mu \mathrm{g} / \mathrm{ml}$ gentamycin sulfate, $0.2 \mathrm{mM}$ sodium pyruvate, $3.67 \mathrm{nM} \mathrm{17 \beta -}$ estradiol, $15.6 \mathrm{nM}$ bovine FSH (Sioux Biochemical, Sioux Center, IA), $156 \mathrm{nM}$ bovine LH (Sioux Biochemical), and
$10 \% \mathrm{v} / \mathrm{v}$ defined fetal bovine serum (FBS) (Hyclone, Logan, $\mathrm{UT})]$ at $38.5{ }^{\circ} \mathrm{C}$ in $5 \% \mathrm{CO}_{2}$ and humidified air for $24 \mathrm{~h}$. IVF was conducted using motile spermatozoa separated by Percoll gradient technique from frozen thawed bovine semen. The matured COCs were co-incubated with motile spermatozoa $\left(1 \times 10^{6} \mathrm{sperm} / \mathrm{ml}\right)$ for 18 $20 \mathrm{~h}$ in fertilization media FIV (114 mM NaCl, $25 \mathrm{mM}$ $\mathrm{NaHCO}_{3}, 3.2 \mathrm{mM} \mathrm{KCl}, 0.34 \mathrm{mM} \mathrm{NaH} \mathrm{PO}_{4}, 0.183 \mathrm{mM}$ penicillin-G, $16.6 \mathrm{mM}$ sodium lactate, $0.5 \mathrm{mM}$ $\mathrm{MgCl}_{2} 6 \mathrm{H}_{2} \mathrm{O}, 2.7 \mathrm{mM} \mathrm{CaCl}_{2} 2 \mathrm{H}_{2} \mathrm{O}, 0.2 \mathrm{mM}$ sodium pyruvate, $6 \mathrm{mg} / \mathrm{ml} \mathrm{BSA}$, and $1.5 \mathrm{U}$ of heparin) at $38.5{ }^{\circ} \mathrm{C}$ in $5 \% \mathrm{CO}_{2}$ and humidified air. After IVM and IVF, the cumulus cells were stripped off by vortexing for $6 \mathrm{~min}$. Then, presumptive zygotes were washed and cultured in potassium simplex optimization medium (KSOM; EMD Millipore, Billerica, MA) supplemented with $0.3 \%$ fatty acid free bovine serum albumin (BSA) until $72 \mathrm{~h}$ post insemination (hpi). Then, 8- to 16-cell stage embryos were separated and cultured in fresh KSOM medium supplemented with $0.3 \%$ BSA and 10\% FBS under same conditions until $\mathrm{d} 7$.

\section{Effect of AKT inhibitors III \& IV on early embryonic development}

AKT inhibitor III, known as SH6, is a cell permeable reversible substrate competitive phosphatidylinositol analog that prevents the generation of PIP3 by PIK3 which is required for $\mathrm{AKT}$ phosphorylation. AKT inhibitor IV is a cell permeable reversible benzimidazole compound that inhibits AKT phosphorylation/activation by targeting the ATP binding site of a kinase upstream of AKT, but downstream of PI3K [28]. The effects of AKT inhibitors III and IV treatment on early embryonic development were investigated as described in Fig. 1. Presumptive zygotes were cultured in KSOM medium supplemented with $0.3 \% \mathrm{BSA}$ in the presence of $0,25,50$ or $75 \mu \mathrm{M}$ AKT inhibitor III (ALX-270-350 - Enzo Life Sciences, Farmingdale, NY), or $0,1.5,2.5$ or $3.5 \mu \mathrm{M}$ AKT inhibitor IV (Sigma, 124,011-1MG) until 72 hpi $(n=25-30$ presumptive zygotes/group, $n=4$ replicates/inhibitor). Embryos at 8- to 16-cell stage were separated, washed and cultured in fresh KSOM medium supplemented with $0.3 \%$ BSA and $10 \%$ FBS in the absence of inhibitor until $d 7$. The effects of AKT inhibition on indices of embryo developmental progression including early cleavage rate determined at 30 hpi, total cleavage rate determined at $48 \mathrm{hpi}$, percentage of embryos developing to the 8- to 16-cell stage at $72 \mathrm{hpi}$ and percentage of embryos developing to the blastocyst stage at $\mathrm{d} 7$ were recorded.

\section{Effect of AKT inhibitors III \& IV on AKT phosphorylation in early bovine embryos}

To investigate the effect of AKT inhibitors III \& IV treatment on AKT signaling activity in bovine embryo, 


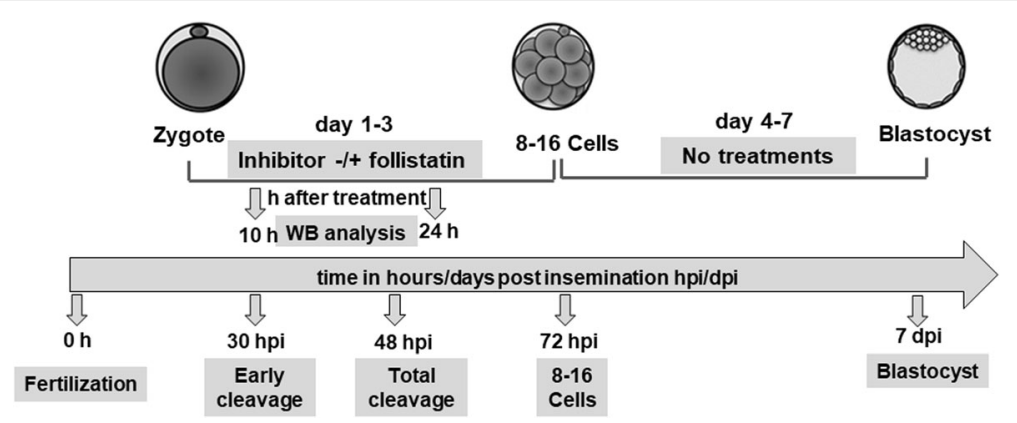

Fig. 1 Experimental design. To establish the role of AKT in early bovine embryonic development, bovine zygotes were cultured in the presence or absence of different doses of AKT inhibitors III or IV for 3 days. The optimized dose of each inhibitor was supplemented with or without $10 \mathrm{ng} / \mathrm{ml}$ follistatin to determine the effects on AKT phosphorylation at $10 \mathrm{~h}$ after treatment and development of AKT inhibitor treated embryos. On day 3 of development, embryos were washed and cultured in fresh media without any treatment for an additional 4 days. Indices of embryo development including early cleavage rate (30 hpi), total cleavage rate (48 hpi), percentage of embryos developing to the 8 - to 16 -cell stage (72 hpi), and percentage of embryos developing to the blastocyst stage (day 7) were recorded

AKT-Ser473 and AKT-Thr308 phosphorylation levels were analyzed. Presumptive zygotes were cultured in KSOM medium supplemented with $0.3 \%$ BSA in the presence of $0,25,50$ or $75 \mu \mathrm{M}$ AKT inhibitor III (Fig. 1) [18], or $0,1.5,2.5$ or $3.5 \mu \mathrm{M}$ AKT inhibitor IV for $10 \mathrm{~h}$. Then, samples were collected for Western blot analysis of phosphorylated (p)-AKT-Ser473 or pAKT-Thr308, total $(\mathrm{t})$-AKT and actin ( $n=3$ replicates/inhibitor/phosphorylation site, $n=20$ presumptive zygotes/group). All the doses of AKT inhibitors used in this study were selected based on previously published studies in bovine and mice $[18,19,21]$.

\section{Effects of follistatin supplementation on the developmental capacity of AKT inhibitor treated bovine embryos}

Experiment was performed as described in Fig. 1. After IVM and IVF, presumptive zygotes were cultured with 0 or $10 \mathrm{ng} / \mathrm{ml}$ recombinant human follistatin (R\&D Systems, Minneapolis, MN) [4] in the presence or absence of AKT inhibitor III $(75 \mu \mathrm{M})$ or AKT inhibitor IV $(3.5 \mu \mathrm{M})$ until 72 hpi ( $n=4$ replicates/inhibitor, $n=20-30$ zygotes/group). Then, 8- to 16-cell stage embryos from each group were separated and cultured in fresh KSOM medium supplemented with $0.3 \% \mathrm{BSA}$ and $10 \% \mathrm{FBS}$ without any treatment until $d$ 7. Effects of exogenous follistatin on early and total cleavage, development to 8-16-cell and d7 blastocyst rates were recorded.

\section{Effect of follistatin supplementation on activity of AKT signaling pathway in AKT inhibitor treated early bovine embryos}

Effects of follistatin supplementation on AKT signaling activity were investigated by analysis of AKT phosphorylation levels at 10 and $24 \mathrm{~h}$ after follistatin supplementation in the presence and absence of AKT inhibitor III or IV (Fig. 1). Presumptive zygotes were cultured with 0 or $10 \mathrm{ng} / \mathrm{ml}$ recombinant human follistatin in the presence or absence of AKT inhibitor III $(75 \mu \mathrm{M})$ or AKT inhibitor IV $(3.5 \mu \mathrm{M})$ during the initial $72 \mathrm{~h}$ of in vitro embryo culture. Samples were collected at $10 \mathrm{~h}$ after treatment administration $(n=6$ replicates/inhibitor, $n=20$ zygotes/group). For the second experiment, follistatin $(0$ or $10 \mathrm{ng} / \mathrm{ml})$ was supplemented during the same time window and samples collected at $24 \mathrm{~h}$ after treatment administration $(n=5$ replicates/inhibitor, $n=20$ zygotes/group). Samples were subjected to Western blot analysis of pAKT-Ser473, pAKT-Thr308, tAKT and actin.

\section{Western blot analysis}

Western blot analysis was performed as described before [3]. Proteins (20 oocytes/embryos per sample) were separated by SDS-PAGE electrophoresis using 4-20\% gradient pre-casted gel (Bio-Rad, Hercules, CA) and transferred to a polyvinylidene difluoride (PVDF, Millipore) membrane. After transfer, membranes were blocked with $5 \%$ BSA in Tris Buffered Saline with 0.5\% Tween 20 (TBST) for $1 \mathrm{~h}$ at room temperature before overnight incubation with the appropriate primary antibody diluted in TBST with $5 \%$ BSA at $4{ }^{\circ} \mathrm{C}$. The membrane was then washed and incubated with the appropriate HRPconjugated secondary antibody diluted in TBST with 5\% BSA for $1 \mathrm{~h}$ at room temperature. Protein signals were detected with SuperSignal West Dura Chemiluminescent Substrate (Thermo Scientific, Waltham, MA) and Images were captured using myECL Imager (Thermo Scientific). ImageJ software was used to measure the band intensities of the target proteins [29]. Relative abundance of each protein was normalized to the total-actin expression in corresponding lane, and phosphorylation level was expressed as phosphorylated (p) AKT/total (t) AKT. Membranes were probed sequentially with primary pAKT-Ser473 rabbit polyclonal antibody [1:1000 (Vol/Vol), Santa Cruz, sc-7985-R] 
or pAKT-Thr308 rabbit polyclonal antibody [1:1000 (Vol/Vol), Cell Signaling Technology, 9275]. After detection of pAKT membranes were striped with restore Western blot stripping buffer (Thermo Scientific) for $15 \mathrm{~min}$ at room temperature and re-probed with tAKT Rabbit polyclonal antibody [1:2000 ( Vol/Vol), Santa Cruz, sc-8312]. After detection of tAKT, membranes were stripped and re-probed with actin monoclonal antibody (1:5000 (Vol/Vol) Millipore; MAB1501). HRPconjugated Anti-Rabbit-IgG (Cell Signaling Technology, 7074), and Anti-Mouse-IgG (Thermo Scientific, A16011) were used as secondary antibodies at a 1:5000 $(\mathrm{Vol} / \mathrm{Vol})$ dilution.

\section{Statistical analysis}

Differences in phosphorylation levels obtained by Western-blot analysis were analyzed by ANOVA using the general linear models' procedure of SAS (SAS Institute Inc., Cary, NC). For experiments studying the effects of AKT inhibitors and follistatin supplementation on early embryonic development, data were arcsine transformed prior to analysis by mixed linear models' analysis procedures. Differences among treatment means were compared using Fisher's protected least significant difference test. In all cases data are presented as untransformed mean \pm standard error $(P<0.05)$.

\section{Results}

AKT inhibition during the initial $72 \mathrm{~h}$ of in vitro culture reduced indices of embryonic developmental progression To elucidate the potential role of AKT in bovine early embryogenesis, effects of AKT inhibitor III and AKT inhibitor IV supplementation (during the initial $72 \mathrm{~h}$ of in vitro embryo culture) on different developmental indices (early cleavage, total cleavage, 8- to 16-cell and blastocyst formation rates) were determined. The addition of 25, 50 and $75 \mu \mathrm{M}$ AKT inhibitor III to the culture medium delayed early cleavage therefore no cleavage was observed at 30 hpi (Fig. 2a). Treatment with AKT inhibitor III significantly reduced the total cleavage rate, percentage of embryos that reached 8- to 16-cell stage at $72 \mathrm{hpi}$, and $\mathrm{d} 7$ blastocyst rate relative to controls at $75 \mu \mathrm{M}$ dose (Fig. 2b-d). However, no significant effects on total cleavage were observed in response to both 25 and $50 \mu \mathrm{M}$ doses compared with control (Fig. 2b, c). Additionally, the 25-mM dose didn't impact the development to 8-to 16-cell or blastocyst stages (Fig. 2c-d). The addition of AKT inhibitor IV resulted in a dose dependent reduction in early cleavage, development to 8- to 16-cell and blastocyst stage with maximum response observed for $3.5 \mu \mathrm{M}$ dose which delayed early cleavage and completely blocked development to blastocyst. Total cleavage wasn't impacted by lower doses of AKT inhibitor IV $(1.5,2.5 \mu \mathrm{M})$ whereas the higher dose $(3.5 \mu \mathrm{M})$ significantly reduced the number of embryos
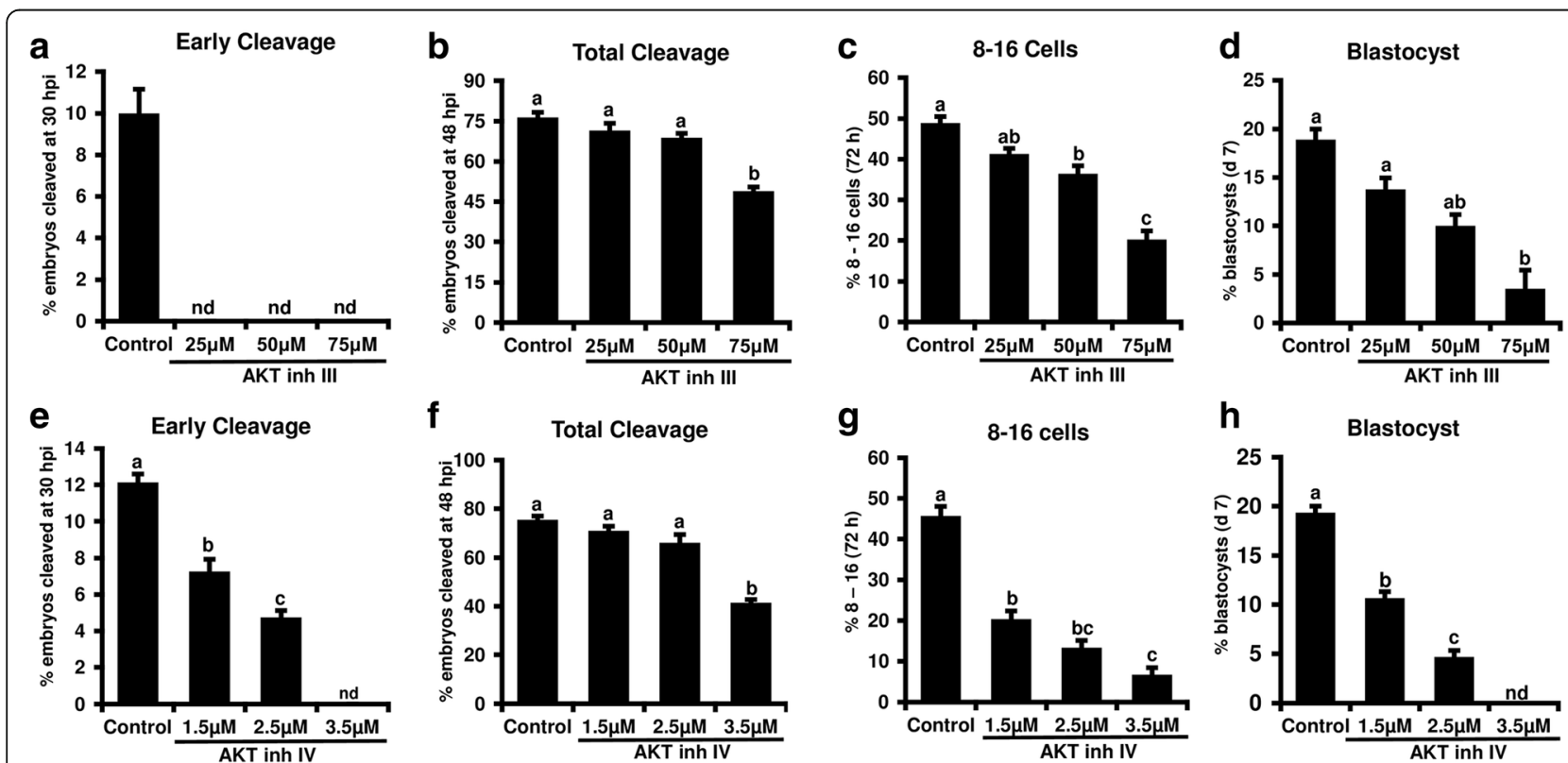

Fig. 2 Effects of AKT inhibitors III and IV treatment on bovine early embryonic development. Presumptive zygotes were cultured in the presence of $0,25,50$ or $75 \mu \mathrm{M}$ AKT inhibitor III or 0, 1.5, 2.5 or $3.5 \mu \mathrm{M}$ AKT inhibitor IV until 72 hpi, then washed and cultured in fresh culture media lacking inhibitors until d 7 ( $n=4$ replicates/inhibitor, $n=25-30$ embryos/treatment). Effects of each AKT inhibitor treatment on (a, e) early cleavage, (b, f) total cleavage, $(\mathbf{c}, \mathbf{g})$ development to 8- to 16-cell stage and $(\mathbf{d}, \mathbf{h}) \mathrm{d}$ 7 blastocyst rates were determined. Data are expressed as mean \pm SEM. Values with different superscripts among treatments indicate significant differences $(P<0.05)$ 
reaching two cells at 48 hpi (Fig. 2e-h). Results demonstrate that inhibition of AKT delayed early embryonic cleavage at $30 \mathrm{hpi}$, and consequently reduced development to the later endpoints, suggesting a potential requirement of AKT for early embryonic development.

\section{Effects of AKT inhibitors III \& IV on AKT phosphorylation in early bovine embryos}

Dose response studies were conducted to determine the effects of different concentrations of AKT inhibitor III $(25,50$, and $75 \mu \mathrm{M})$ or AKT inhibitor IV $(1.5,2.5$ and $3.5 \mu \mathrm{M})$ on AKT-Ser 473 and Thr308 phosphorylation levels in early embryos after $10 \mathrm{~h}$ of treatment. AKTThr308 phosphorylation level was significantly reduced in response to high doses of AKT inhibitor III $(75 \mu \mathrm{M})$ and AKT inhibitor IV $(3.5 \mu \mathrm{M})$ whereas slight non-significant reduction $(P<.09)$ in phosphorylation level was also observed with lower doses of AKT inhibitor III $(25$ or $50 \mu \mathrm{M})$ or AKT inhibitor IV (1.5 and $2.5 \mu \mathrm{M})$ (Fig. 3a, b). On the other hand, AKT-Ser473 phosphorylation level was not impacted by treatment with the $25 \mu \mathrm{M}$ AKT inhibitor III dose, whereas 50, and $75 \mu \mathrm{M}$ doses, resulted in a significant reduction after $10 \mathrm{~h}$ of supplementation (Additional file 1: Figure S1a). Treatment with AKT inhibitor IV didn't show any effect on AKT-Ser437 phosphorylation at this time point (Additional file 1: Figure S1b).

Follistatin supplementation rescues the adverse effects of AKT inhibition on early embryo development

Our previous studies established a functional requirement of maternally derived follistatin for bovine early embryogenesis and embryotrophic effects of exogenous follistatin supplementation on early embryo development including enhanced early cleavage, and increased blastocyst formation rate and trophectoderm cell numbers. The AKT signaling pathway is regulated by members of TFG- $\beta$ superfamily [8]. Hence, we investigated if follistatin supplementation can rescue the negative effects of AKT inhibition on early embryonic development. In the absence of the AKT inhibitors, follistatin supplementation $(10 \mathrm{ng} / \mathrm{ml})$ significantly increased the proportion of embryos reaching 2-cell stage at $30 \mathrm{hpi}$ (early cleavage), the proportion of embryos reaching 8 to 16-cell stage at $72 \mathrm{~h}$ and $\mathrm{d} 7$ blastocyst rates compared with untreated controls. In addition, follistatin supplementation rescued the inhibitory effects of AKT inhibitors on early embryonic development (Fig. 4a-h). Follistatin supplementation was able to rescue the effects of AKT inhibitor III on early cleavage, total cleavage and development to 8- to 16-cell stage to levels similar to controls (Fig. 4a-c), and to partially rescue the effects of AKT inhibitor III on blastocyst development rate (Fig. 4d). Using AKT inhibitor IV with same experimental design, we observed that follistatin supplementation $(10 \mathrm{ng} / \mathrm{ml})$ partially rescued the negative effects of AKT inhibitor IV on total cleavage, early cleavage, 8 - to 16-cell and blastocysts development rates (Fig. 4e-h). Collectively, results suggest a potential requirement of AKT for bovine early embryonic development, and a possible relationship between the embryotrophic actions of follistatin and the AKT signaling pathway.

Follistatin supplementation modulates the AKT signaling pathway in early bovine embryos

Our results revealed that exogenous follistatin could rescue the negative effects of AKT inhibition on various developmental endpoints in bovine embryos. Therefore, we analyzed the effect of exogenous follistatin supplementation
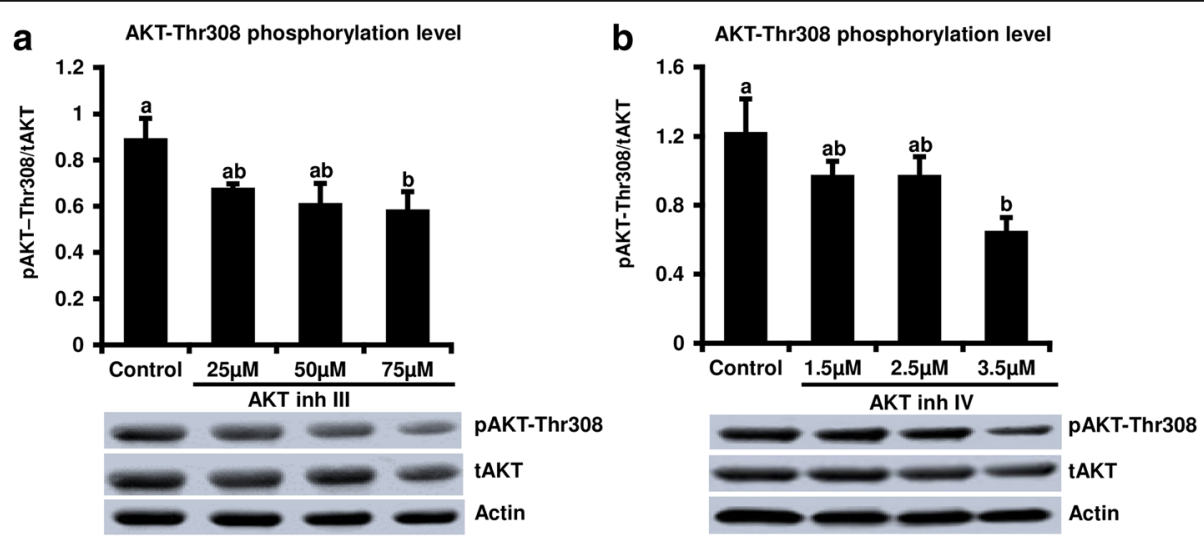

Fig. 3 Effect of AKT inhibitors III and IV treatments on AKT-Thr308 phosphorylation levels in early bovine embryos. Presumptive zygotes were cultured in presence of $0,25,50$ or $75 \mu \mathrm{M}$ AKT inhibitor III or 0, 1.5, 2.5 or $3.5 \mu \mathrm{M}$ AKT inhibitor IV for $10 \mathrm{~h}$, then subjected to Western blot for phosphorylated (p)AKt-Th308, total AKT (tAKT) and actin analysis ( $n=3$ replicates, $n=20$ embryos/treatment). Data were normalized relative to abundance of actin and phosphorylation levels were expressed as pAKT/tAKT $(\mathbf{a}, \mathbf{b})$. Representative Western blot images are shown. Data are expressed as mean \pm SEM. Values with different superscripts among treatments indicate significant differences $(P<0.05)$ 


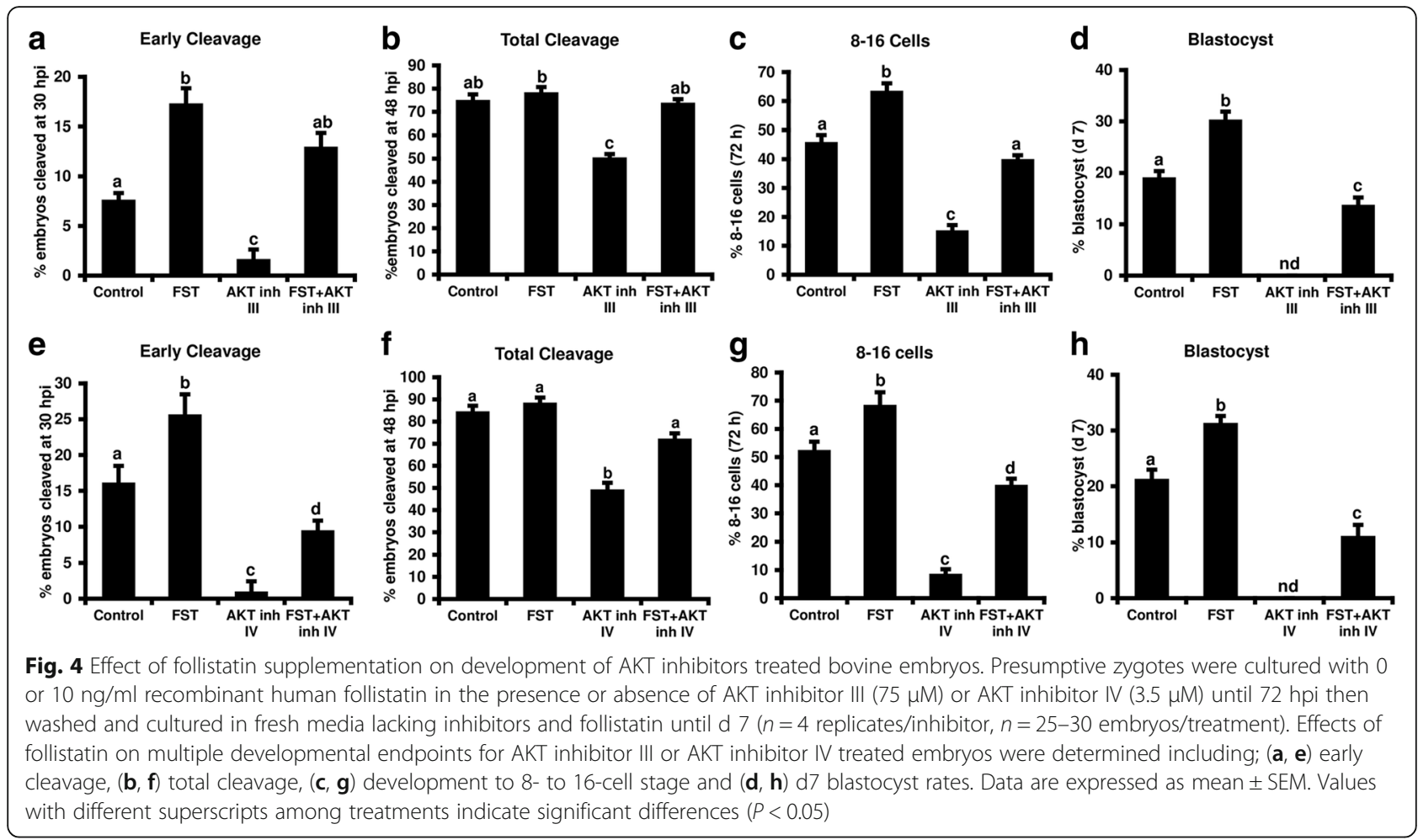

on AKT signaling activity in the presence or absence of AKT inhibitors to determine whether follistatin rescue the effects of AKT inhibition through modulation of AKT signaling. Western blot analysis showed that AKT inhibitor IV treatment resulted in a significant reduction in AKT-Thr308 phosphorylation level in zygotes $10 \mathrm{~h}$ post treatment that was rescued by supplementation with exogenous follistatin. However, no effect of follistatin treatment on basal levels of AKT phosphorylation was observed in the absence of inhibitor treatment (Fig. 5a). Similar pattern was observed in response to AKT inhibitor III treatment (Additional file 2: Figure S2a). We further investigated if follistatin supplementation has any effect on basal
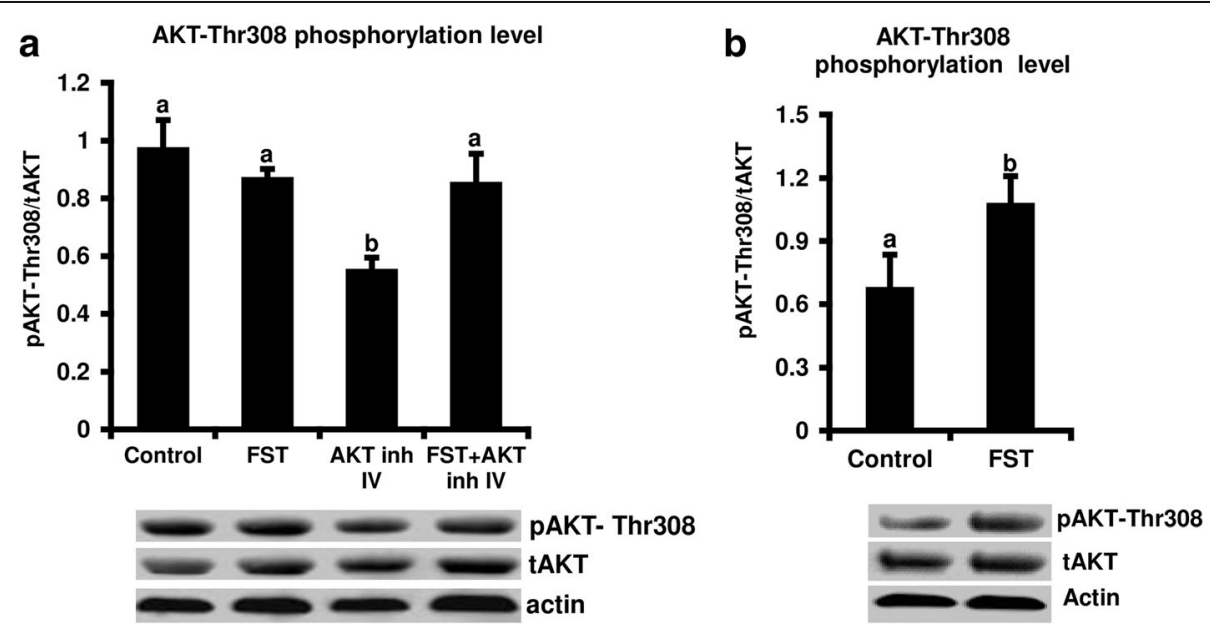

Fig. 5 Effect of follistatin treatment on AKT-Thr308 phosphorylation levels in early bovine embryos. Presumptive zygotes were cultured with 0 or $10 \mathrm{ng} / \mathrm{ml}$ recombinant human follistatin in the presence or absence of AKT inhibitor IV (3.5 $\mu \mathrm{M})$ for $10 \mathrm{~h}$ ( $n=5$ replicates, $n=20$ zygotes/group) (a), or Presumptive zygotes were cultured in the presence or absence of $10 \mathrm{ng} / \mathrm{ml}$ follistatin for $24 \mathrm{~h}$ ( $n=5$ replicates, $n=20$ zygotes/group) (b). Samples were subjected to Western blot analysis for pAKT-Thr308, tAKT and Actin. Expression levels were normalized to the abundance of an endogenous control actin. Phosphorylation level was expressed as PAKT/tAKT. Data are expressed as mean \pm standard error. Values with different superscripts among treatments indicate significant differences $(P<0.05)$. Representative Western blots are shown 
AKT phosphorylation at a later time point. At $24 \mathrm{~h}$ post treatment administration, follistatin supplementation resulted in a significant increase in AKT phosphorylation relative to embryos cultured in the absence of follistatin (Fig. 5b, Additional file 2: Figure S2b).

\section{Discussion}

A growing body of evidence supports an important intrinsic role for follistatin in bovine oocyte quality and early embryo developmental progression in vitro $[3,4$, $11,12]$. While follistatin is best known for its ability to bind and inhibit activity of select TGF- $\beta$ superfamily ligands, the intrinsic ligands and signaling pathways linked to trophic actions of follistatin on early embryos are not known. Results of the present study demonstrated that pharmacological inhibition of AKT signaling pathway in early bovine embryos reduced their developmental capacity as assessed by early cleavage, total cleavage and rates of development to 8-16-cell and blastocyst stages. Follistatin supplementation during the first $72 \mathrm{~h}$ of in vitro embryo culture rescued the adverse effects of AKT signaling inhibition on embryo development and increased the level of AKT phosphorylation, suggesting a potential role for follistatin in regulation of AKT signaling in early bovine embryos. Results demonstrate follistatin regulation of non-canonical TGF-beta superfamily signaling in bovine embryos and a functional link to developmental progression.

AKT is serine/threonine-specific protein kinase that regulates crucial cellular processes such as glucose metabolism, transcription, cellular growth and proliferation [30-32]. Full activation of AKT requires translocation to the plasma membrane and phosphorylation at Thr308 and Ser473 motifs [33]. Previous studies have established a functional role of AKT during oocyte maturation in various species including bovine [18] and in early embryogenesis in mouse and pigs $[19,20,34]$. In bovine embryo, activation of PI3K/AKT pathway by insulin like growth factor - 1 (IGF-1) has been shown to block heat shock induced apoptosis [35]. In addition, pharmacological inhibition of PI3K, upstream kinase of AKT, using LY294002 resulted in significant decrease in total cleavage, 8 cells and blastocyst development rates in bovine [36]. In the present study, we used two different pharmacological inhibitors of AKT activity to investigate its role in early bovine embryo development. Pharmacological inhibition was selected over siRNA mediated knockdown because inhibitors are membrane permeable and can function immediately by specifically targeting AKT activity without affecting its total protein abundance in embryo. As inhibitors can function in reversible manner, this allowed us to inhibit AKT signaling for define period (d1-3) of in vitro embryo culture in this study. Our does dependent study showed that AKT inhibitor III at $75 \mu \mathrm{m}$ or AKT inhibitor IV at $3.5 \mu \mathrm{M}$ doses exhibited about $50 \%$ reduction in AKT phosphorylation levels and therefore were selected as most effective dose to inhibit AKT signaling. These results were in accordance with the previously published studies in bovine and mice $[18,19,21]$. In addition, higher doses of AKT inhibitor III used in this study has been previously reported to have no nonspecific effect on other kinases downstream to PDK1 [18].

Our results showed that inhibition of AKT during first 3 days of in vitro embryo culture (before zygotic genome activation) resulted in pronounced reduction in multiple indices of early embryonic development. Early embryonic cleavage at $30 \mathrm{hpi}$ was not detected for all tested doses of AKT inhibitor III. Total cleavage, rates of development to 8- to 16-cell and day 7 blastocyst rates were significantly reduced in embryos treated with the highest dose of AKT inhibitor III. We observed similar effects of AKT signaling inhibition on embryo development using AKT inhibitor IV. Data from other species [37, 38] suggest that AKT is implicated in regulation of mitotic cell cycle transition from $\mathrm{G} 2$ to $\mathrm{M}$ phase through activation of M-phase promoting factor (MPF). Therefore, upon inhibition of $\mathrm{AKT}$, the MPF complex remains inactive and the cells are arrested in G1 or G2 stages of the cell cycle [24, 39]. Reduction of AKT phosphorylation/activity may delay cell cycle progression [40] or compromise the developmental capacity of treated embryos. Therefore, early cleavage at $30 \mathrm{hpi}$ was not detected, and total cleavage, development to 8- to 16-cell and blastocyst stages were reduced compared with untreated embryos. Collectively, these results demonstrated that inhibition of AKT signaling using two different AKT inhibitors similarly reduced the development of early bovine embryos in vitro suggesting an important functional role of AKT signaling in early bovine embryogenesis. However, further mechanistic studies are required to conclusively elucidate how the AKT signaling pathway regulates early embryonic development in bovine.

We previously established a positive association between follistatin and oocyte developmental competence $[2,3]$. Supplementation of exogenous follistatin during in vitro embryo culture has embryotropic effects in bovine and non-human primates $[4,41]$. Although, follistatin was originally identified as an activin antagonist [13], the embryotropic actions of follistatin are presumably not mediated by inhibition of activin action as exogenous supplementation of activin mimicked the embryotrophic effects of follistatin [4]. As a TGF- $\beta$ superfamily growth factor binding protein, follistatin may exert its embryotrophic actions by modulating SMAD dependent (SMAD1/5/8 or SMAD2/3) or non-SMAD dependent (AKT, ERK, P38 and JNK) pathways implicated in signaling by this growth factor family [8]. Previous studies in 
our laboratory demonstrated that, exogenous follistatin supplementation rescued the effects of SMAD2/3 and SMAD4 inhibition/knockdown on early cleavage but not the effects on development to 8- to 16-cell and blastocyst stages, suggesting that the embryotrophic effects of follistatin on early cleavage are SMAD independent [11, 12]. In the current study, the effects of follistatin supplementation on development of AKT inhibitor treated embryos were investigated. Treatment with $10 \mathrm{ng} / \mathrm{ml}$ follistatin during the initial $72 \mathrm{~h}$ of in vitro embryo culture reversed the inhibitory effects of AKT inhibitor III on early cleavage, total cleavage and development to the 8 - to 16-cell stage and partially rescued development to the blastocyst stage. Results also demonstrated that AKT inhibitors significantly reduced the levels of AKT phosphorylation in the absence of follistatin. In addition, follistatin treatment not only reverse the AKT inhibitors effect on phosphorylation level but also increase the AKT phosphorylation when supplemented independently for $24 \mathrm{~h}$. These results suggest that follistatin may be playing a role in returning the AKT phosphorylation to the levels required for rescuing the adverse effect of AKT inhibitors on early cleavage. Collectively, results suggest a potential functional link between follistatin action and AKT signaling linked to its embryotropic actions in bovine embryos. As the effects of other signaling pathways can't be disregarded, further studies may be required to elucidate the effects of inhibition of multiple signaling pathways on the development of early bovine embryos and to dissect the specific effects of each signaling pathway.

Effects of TGF- $\beta$ superfamily stimulation on AKT signaling appear to be pleiotropic and cell type dependent. It has been demonstrated that members of TGF- $\beta$ superfamily activate PI3K pathway through phosphorylation of its downstream effector AKT [42-44]. TGF- $\beta$ can induce a physical interaction between the p85 regulatory subunit of PI3K and the TRRII and T $\beta R I$ receptors converting phosphatidylinositol-4,5-bisphosphate $\left(\mathrm{PIP}_{2}\right)$ to phosphatidylinositol-3,4,5-triphosphate $\left(\mathrm{PIP}_{3}\right)$ and subsequently AKT phosphorylation [45-47]. Studies on somatic cell lines indicate that follistatin treatment activates PI3K/AKT signaling pathway [48, 49]. In the present studies, follistatin treatment reversed the inhibitory effects of AKT inhibitor treatment on AKT phosphorylation levels at $10 \mathrm{~h}$ post treatment, but a follistatin dependent increase in basal AKT phosphorylation was not observed in the absence of AKT inhibitor treatment. However, follistatin treatment did increase basal AKT phosphorylation levels $24 \mathrm{~h}$ post treatment administration. The exact reason for time dependent effects on AKT signaling observed in response to follistatin treatment are not known but may be reflecting time/treatment induced differences in endogenous growth factor milieu and bioaffinity for specific ligands. Results suggest that follistatin plays a role in regulation of AKT signaling in early bovine embryos. However, AKT seems to not be required for the embryotrophic actions of follistatin.

\section{Conclusions}

Results of the present study demonstrate that inhibition of AKT signaling reduce the developmental competence of early bovine embryos suggesting a potential requirement of AKT signaling for bovine early embryonic development. Follistatin supplementation rescued the developmental competence of AKT inhibitor treated embryos suggesting that the examined embryotrophic effects of follistatin do not require AKT signaling. However, follistatin supplementation increased the relative abundance of pAKT in AKT inhibitor treated embryos and increased the level of AKT phosphorylation when supplemented without AKT inhibitor, suggesting that follistatin plays a role in regulation of AKT signaling in early bovine embryos. Together, the results reported here, provide additional insights into understanding the regulation of early embryonic development and the mechanism of action of the embryotrophic agent, follistatin, in early bovine embryos.

\section{Additional files}

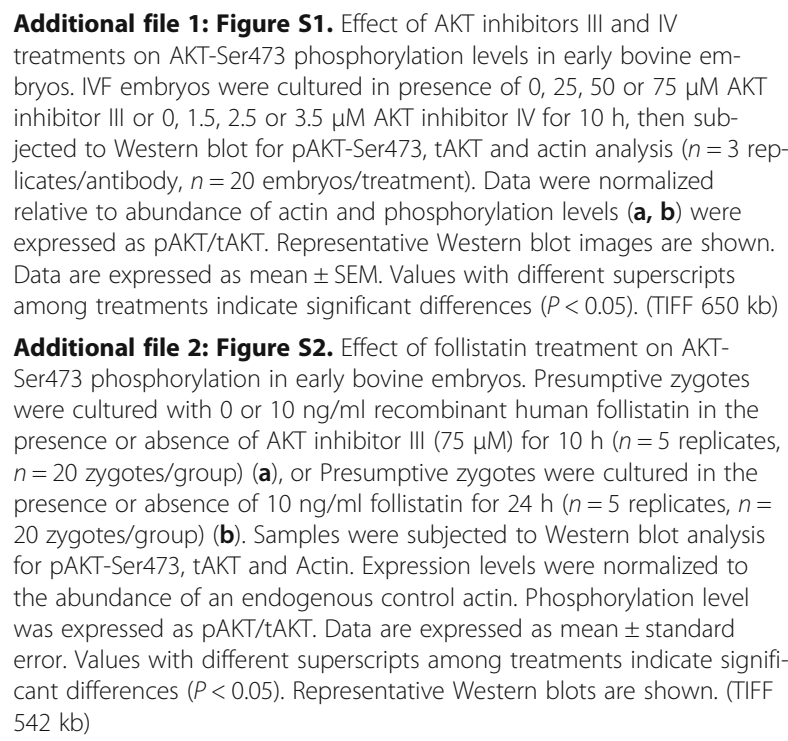

Additional file 2: Figure S2. Effect of follistatin treatment on AKTSer473 phosphorylation in early bovine embryos. Presumptive zygotes were cultured with 0 or $10 \mathrm{ng} / \mathrm{ml}$ recombinant human follistatin in the presence or absence of AKT inhibitor III $(75 \mu \mathrm{M})$ for $10 \mathrm{~h}$ ( $n=5$ replicates, $n=20$ zygotes/group) (a), or Presumptive zygotes were cultured in the presence or absence of $10 \mathrm{ng} / \mathrm{ml}$ follistatin for $24 \mathrm{~h}$ ( $n=5$ replicates, $n=$ 20 zygotes/group) (b). Samples were subjected to Western blot analysis for pAKT-Ser473, tAKT and Actin. Expression levels were normalized to the abundance of an endogenous control actin. Phosphorylation level was expressed as pAKT/tAKT. Data are expressed as mean \pm standard error. Values with different superscripts among treatments indicate significant differences $(P<0.05)$. Representative Western blots are shown. (TIFF $542 \mathrm{~kb}$ )

\footnotetext{
Abbreviations

AKT/PKB: Protein Kinase B; BMPs: Bone Morphogenetic Proteins; BSA: Bovine Serum Albumin; CDK1: Cyclin Dependent Kinase 1; COCs: Cumulus Oocyte Complexes; D: Day; Dpi: Days post insemination; FBS: Fetal Bovine Serum; FSH: Follicle Stimulating Hormone; H: Hour; Hpi: Hour Post Insemination; IGF1: Insulin Like Growth Factor - 1; Inh: Inhibitor; IVC: In Vitro Culture; IVF: In Vitro Fertilization; IVM: In Vitro Maturation; KSOM: Potassium Simplex Optimization Medium; LH: Luteinizing Hormone; Ml: Metaphase I; MII: Metaphase II; pAKT: Phosphorylated AKT; PDE3A: Phosphodiesterase 3A; PVDF: Polyvinylidene Difluoride; Ser: Serine; tAKT: Total AKT; TBST: Tris Buffered Saline; TGF- $\beta$ : Transforming growth factor $\beta$; Thr: Threonine; WB: Western blotting; $\mu \mathrm{M}$ : Micro molar
} 


\section{Acknowledgements}

Not applicable.

\section{Funding}

This study was supported by the National Institute of Child Health and Human Development of the National Institutes of Health under award number R01HD072972 and by Michigan State University AgBioResearch. MA was supported by the Egyptian Government Joint supervision grant JS2687. The funding agencies had no role neither in study design, data collection, analysis, or interpretation nor in the writing of the report; or in the decision to submit the paper for publication.

\section{Availability of data and materials}

Data sharing is not applicable to this article as no datasets were generated or analysed during the current study.

\section{Authors' contributions}

This study was conceptualized and designed by MA, SKR, JKF and GWS. Investigations and data curation were done by MA with guidance of SKR Fund acquisition was done by GWS, JGK and MA. Statistical analysis was done by MA and JKF. Original draft was prepared by MA, reviews and editing were completed by MA, SKR, JKF, JGK, NAH, OMK, RSR and GWS. All authors read and approved the final manuscript.

\section{Ethics approval and consent to participate}

Ovaries were collected from local slaughter house in the state of Michigan. Michigan State university institutional animal care and use committee (IACUC) doesn't require approval for this study.

\section{Consent for publication}

Not applicable.

\section{Competing interests}

The authors declare that they have no competing interests.

\section{Publisher's Note}

Springer Nature remains neutral with regard to jurisdictional claims in published maps and institutional affiliations.

\section{Author details}

'Laboratory of Mammalian Reproductive Biology and Genomics, Michigan State University, East Lansing, MI 48824, USA. ${ }^{2}$ Developmental Epigenetics Laboratory, Michigan State University, East Lansing, Ml 48824, USA. ${ }^{3}$ Department of Animal Science, Michigan State University, East Lansing, MI 48824, USA. ${ }^{4}$ Department of Theriogenology, Faculty of Veterinary Medicine, Cairo University, Giza, Egypt. ${ }^{5}$ Department of Animal Reproduction and Artificial Insemination, Veterinary Research Division, National Research Center, Giza, Egypt.

Received: 22 September 2017 Accepted: 25 December 2017 Published online: 08 January 2018

\section{References}

1. Ashry M, Smith GW. Application of embryo transfer using in vitro produced embryos: intrinsic factors affecting efficiency. Cattle Practice. 2015;23:8.

2. Patel OV, Bettegowda A, Ireland JJ, Coussens PM, Lonergan P, Smith GW Functional genomics studies of oocyte competence: evidence that reduced transcript abundance for follistatin is associated with poor developmental competence of bovine oocytes. Reproduction. 2007:133:95-106.

3. Ashry M, Lee K, Mondal M, Datta TK, Folger JK, Rajput SK, Zhang K, Hemeida NA, Smith GW. Expression of TGFbeta superfamily components and other markers of oocyte quality in oocytes selected by brilliant cresyl blue staining: relevance to early embryonic development. Mol Reprod Dev. 2015;82:251-64.

4. Lee KB, Bettegowda A, Wee G, Ireland JJ, Smith GW. Molecular determinants of oocyte competence: potential functional role for maternal (oocytederived) follistatin in promoting bovine early embryogenesis. Endocrinology. 2009;150:2463-71

5. Rajput SK, Lee K, Zhenhua G, Di L, Folger JK, Smith GW. Embryotropic actions of follistatin: paracrine and autocrine mediators of oocyte competence and embryo developmental progression. Reprod Fertil Dev. 2013;26:37-47
6. Moustakas A, Souchelnytskyi S, Heldin CH. Smad regulation in TGF-beta signal transduction. J Cell Sci. 2001:114:4359-69.

7. Attisano L, Wrana JL. Signal transduction by the TGF-beta superfamily. Science. 2002:296:1646-7.

8. Z Zhang YE. Non-Smad pathways in TGF-beta signaling. Cell Res. 2009;19:128-39.

9. Mu Y, Gudey S, Landström M. Non-Smad signaling pathways. Cell Tissue Res. 2012;347:11-20.

10. Ikushima H, Miyazono K. TGFbeta signalling: a complex web in cancer progression. Nat Rev Cancer. 2010;10:415-24.

11. Zhang K, Rajput SK, Lee KB, et al. Evidence supporting a role for SMAD2/3 in bovine early embryonic development: potential implications for Embryotropic actions of Follistatin. Biol Reprod. 2015;93(4):86.

12. Lee KB, Zhang K, Folger JK, Knott JG, Smith GW. Evidence supporting a functional requirement of SMAD4 for bovine preimplantation embryonic development: a potential link to embryotrophic actions of follistatin. Biol Reprod. 2014;91:62.

13. Nakamura T, Takio K, Eto $Y$, Shibai H, Titani K, Sugino H. Activin-binding protein from rat ovary is follistatin. Science. 1990;247:836-8.

14. lemura S, Yamamoto TS, Takagi C, Uchiyama H, Natsume T, Shimasaki S, Sugino $H$, Ueno N. Direct binding of follistatin to a complex of bonemorphogenetic protein and its receptor inhibits ventral and epidermal cell fates in early Xenopus embryo. Proc Natl Acad Sci U S A. 1998;95:9337-42.

15. Lin SY, Morrison JR, Phillips DJ, de Kretser DM. Regulation of ovarian function by the TGF-beta superfamily and follistatin. Reproduction. 2003;126:133-48.

16. Ghosh-Choudhury N, Abboud SL, Nishimura R, Celeste A, Mahimainathan L, Choudhury GG. Requirement of BMP-2-induced phosphatidylinositol 3kinase and Akt serine/threonine kinase in osteoblast differentiation and Smad-dependent BMP-2 gene transcription. J Biol Chem. 2002;277:33361-8.

17. Do TV, Kubba LA, Antenos M, Rademaker AW, Sturgis CD, Woodruff TK. The role of activin a and Akt/GSK signaling in ovarian tumor biology. Endocrinology. 2008;149:3809-16.

18. Tomek W, Smiljakovic T. Activation of Akt (protein kinase B) stimulates metaphase I to metaphase II transition in bovine oocytes. Reproduction. 2005:130:423-30

19. Kalous J, Kubelka M, Solc P, Susor A, Motlik J. AKT (protein kinase B) is implicated in meiotic maturation of porcine oocytes. Reproduction. 2009; 138:645-54.

20. Kalous J, Solc P, Baran V, Kubelka M, Schultz RM, Motlik J. PKB/AKT is involved in resumption of meiosis in mouse oocytes. Biol Cell. 2006;98:111-23.

21. Hoshino $Y$, Sato E. Protein kinase B (PKB/Akt) is required for the completion of meiosis in mouse oocytes. Dev Biol. 2008;314:215-23.

22. Andersen $C B$, Roth $R A$, Conti $M$. Protein kinase B/Akt induces resumption of meiosis in Xenopus oocytes. J Biol Chem. 1998;273:18705-8.

23. Bellacosa A, Testa JR, Staal SP, Tsichlis PN. A retroviral oncogene, akt, encoding a serine-threonine kinase containing an $\mathrm{SH}$-like region. Science. 1991;254:274-7

24. Baran V, Fabian D, Rehak P. Akt/PKB plays role of apoptosis relay on entry into first mitosis of mouse embryo. Zygote. 2013;21:406-16.

25. Li Y, Chandrakanthan V, Day ML, O'Neill C. Direct evidence for the action of phosphatidylinositol $(3,4,5)$-trisphosphate-mediated signal transduction in the 2-cell mouse embryo. Biol Reprod. 2007;77:813-21.

26. Riley JK, Carayannopoulos MO, Wyman AH, Chi M, Ratajczak CK, Moley KH. The PI3K Akt pathway is present and functional in the preimplantation mouse embryo. Dev Biol. 2005;284:377-86.

27. Bettegowda A, Patel OV, Ireland JJ, Smith GW. Quantitative analysis of messenger RNA abundance for ribosomal protein L-15, cyclophilin-a, phosphoglycerokinase, beta-glucuronidase, glyceraldehyde 3-phosphate dehydrogenase, beta-actin, and histone $\mathrm{H} 2 \mathrm{~A}$ during bovine oocyte maturation and early embryogenesis in vitro. Mol Reprod Dev. 2006;73:267-78.

28. Bhutani J, Sheikh A, Niazi AK. Akt inhibitors: mechanism of action and implications for anticancer therapeutics. Infect Agent Cancer. 2013;8:49.

29. Schneider CA, Rasband WS, Eliceiri KW. NIH image to ImageJ: 25 years of image analysis. Nat Meth. 2012;9:671-5.

30. Kandel ES, Skeen J, Majewski N, Di Cristofano A, Pandolfi PP, Feliciano CS, Gartel A, Hay N. Activation of Akt/protein kinase B overcomes a $G(2) / m$ cell cycle checkpoint induced by DNA damage. Mol Cell Biol. 2002;22: 7831-41.

31. Song G, Ouyang G, Bao S. The activation of Akt/PKB signaling pathway and cell survival. J Cell Mol Med. 2005;9:59-71.

32. Kandel ES, Hay N. The regulation and activities of the multifunctional serine/ Threonine Kinase Akt/PKB. Exp Cell Res. 1999;253:210-29. 
33. Downward J. Mechanisms and consequences of activation of protein kinase B/Akt. Curr Opin Cell Biol. 1998;10:262-7.

34. Feng C, Yu A, Liu Y, Zhang J, Zong Z, Su W, Zhang Z, Yu D, Sun QY, Yu B. Involvement of protein kinase B/AKT in early development of mouse fertilized eggs. Biol Reprod. 2007;77:560-8.

35. Jousan FD, Oliveira LJ, Hansen PJ. Short-term culture of in vitro produced bovine preimplantation embryos with insulin-like growth factor-i prevents heat shock-induced apoptosis through activation of the Phosphatidylinositol 3-Kinase/Akt pathway. Mol Reprod Dev. 2008;75:681-8.

36. Aparicio IM, Garcia-Herreros M, Fair T, Lonergan P. Identification and regulation of glycogen synthase kinase-3 during bovine embryo development. Reproduction. 2010;140:83-92

37. Katayama K, Fujita N, Tsuruo T. Akt/protein kinase B-dependent phosphorylation and inactivation of WEE1Hu promote cell cycle progression at G2/M transition. Mol Cell Biol. 2005:25:5725-37.

38. Okumura E, Fukuhara T, Yoshida H, Hanada Si S, Kozutsumi R, Mori M, Tachibana K, Kishimoto T. Akt inhibits Myt1 in the signalling pathway that leads to meiotic G2/M-phase transition. Nat Cell Biol. 2002;4:111-6.

39. Roberts EC, Shapiro PS, Nahreini TS, Pages G, Pouyssegur J, Ahn NG. Distinct cell cycle timing requirements for extracellular signal-regulated kinase and phosphoinositide 3 -kinase signaling pathways in somatic cell mitosis. Mol Cell Biol. 2002:22:7226-41.

40. Ornelas IM, Silva TM, Fragel-Madeira L, Ventura ALM. Inhibition of PI3K/Akt pathway impairs G2/M transition of cell cycle in late developing progenitors of the avian embryo retina. PLoS One. 2013;8:e53517.

41. VandeVoort CA, Mtango NR, Lee YS, Smith GW, Latham KE. Differential effects of follistatin on nonhuman primate oocyte maturation and preimplantation embryo development in vitro. Biol Reprod. 2009;81:1139-46.

42. Bakin AV, Tomlinson AK, Bhowmick NA, Moses HL, Arteaga CL. Phosphatidylinositol 3-kinase function is required for transforming growth factor beta-mediated epithelial to mesenchymal transition and cell migration. J Biol Chem. 2000;275:36803-10.

43. Lamouille S, Derynck R. Cell size and invasion in TGF-beta-induced epithelial to mesenchymal transition is regulated by activation of the mTOR pathway. J Cell Biol. 2007;178:437-51.

44. Lamouille S, Xu J, Derynck R. Molecular mechanisms of epithelial-mesenchymal transition. Nat Rev Mol Cell Biol. 2014;15:178-96.

45. Yi JY, Shin I, Arteaga CL. Type I transforming growth factor beta receptor binds to and activates phosphatidylinositol 3-kinase. J Biol Chem. 2005;280: 10870-6.

46. Moustakas A, Heldin C-H. Non-Smad TGF- $\beta$ signals. J Cell Sci. 2005;118: 3573-84.

47. Guo X, Wang XF. Signaling cross-talk between TGF-beta/BMP and other pathways. Cell Res. 2009;19:71-88.

48. Winbanks CE, Weeks KL, Thomson RE, Sepulveda PV, Beyer C, Qian H, Chen $J$ L, Allen JM, Lancaster Gl, Febbraio MA, et al. Follistatin-mediated skeletal muscle hypertrophy is regulated by Smad3 and mTOR independently of myostatin. J Cell Biol. 2012;197:997-1008.

49. Li X, Liu H, Wang H, Sun L, Ding F, Sun W, Han C, Wang J. Follistatin could promote the proliferation of duck primary myoblasts by activating PI3K/Akt/ mTOR signalling. Biosci Rep. 2014;34:e00143.

\section{Submit your next manuscript to BioMed Central and we will help you at every step:}

- We accept pre-submission inquiries

- Our selector tool helps you to find the most relevant journal

- We provide round the clock customer support

- Convenient online submission

- Thorough peer review

- Inclusion in PubMed and all major indexing services

- Maximum visibility for your research

Submit your manuscript at www.biomedcentral.com/submit

) Biomed Central 